Title: Spatial characterization of arbuscular mycorrhizal fungal molecular diversity at the submetre scale in a temperate grassland

Author(s): Daniel L. Mummey, Matthias C. Rillig

Document type: Postprint

Terms of Use: $\quad$ Copyright applies. A non-exclusive, non-transferable and limited right to use is granted. This document is intended solely for personal, non-commercial use.

Citation:

This is a pre-copyedited, author-produced version of an article accepted for publication in FEMS Microbiology Ecology following peer review. The version of record:

Mummey, D. L., \& Rillig, M. C. (2008). Spatial characterization of arbuscular mycorrhizal fungal molecular diversity at the submetre scale in a temperate grassland. FEMS Microbiology Ecology, 64(2), 260-270. https://doi.org/10.1111/j.1574-6941.2008.00475.x

is available online at: $h$ ttps://doi.org/10.1111/j.1574-6941.2008.00475.x. 


\section{MICROBIOLOGY ECOLOGY}

http://mc.manuscriptcentral.com/fems

\section{Spatial characterization of arbuscular mycorrhizal fungal molecular diversity at the sub-metre scale in a temperate grassland.}

\begin{tabular}{|r|l|}
\hline Journal: & FEMS Microbiology Ecology \\
\hline Manuscript ID: & FEMSEC-07-11-0512.R2 \\
\hline Manuscript Type: & Research Paper \\
\hline Date Submitted by the \\
Author: & 18 -Jan-2008 \\
\hline Complete List of Authors: & $\begin{array}{l}\text { Mummey, Daniel; University of Montana, Division of Biological } \\
\text { Sciences } \\
\text { Rillig, Matthias; Freie Universitaet Berlin, Plant Ecology }\end{array}$ \\
\hline Keywords: & arbuscular mycorrhizal fungi, spatial variability, T-RFLP, AMF \\
\hline
\end{tabular}

\section{S) ScholarONE" \\ Manuscript Central}




\section{Spatial characterization of arbuscular mycorrhizal fungal molecular diversity}

2 at the sub-metre scale in a temperate grassland.

\section{Daniel L. Mummey ${ }^{1}$ and Matthias C. Rillig ${ }^{2}$}

$4 \mathbf{1}^{1}$ The University of Montana, Division of Biological Sciences, 32 Campus Dr., Missoula, MT,

5 USA, 59812.

$6{ }^{2}$ Freie Universität Berlin, Institut für Biologie, Plant Ecology, Altensteinstr. 6, D- 14195 Berlin,

7 Germany

8 Key words: arbuscular mycorrhizal fungi, spatial variability, spatial autocorrelation, T-RFLP

12 Corresponding author: Daniel L. Mummey,

13 Postal address: The University of Montana, Division of Biological Sciences

14

15 32 Campus Dr., Missoula, MT, USA, 59812.

16

17

\section{Abstract}

20 Although arbuscular mycorrhizal fungi form spatially complex communities in terrestrial

21 ecosystems, the scales at which this diversity manifests itself is poorly understood. This

22 information is critical to the understanding of the role of AMF in plant community composition. 
1 We examined small-scale (sub-metre) variability of AMF community composition (T-RFLP

2 fingerprinting) and abundance (extraradical hyphal lengths) in two $1 \mathrm{~m}^{2}$ plots situated in a native

3 grassland ecosystem of western Montana. Extraradical AMF hyphal lengths varied greatly

4 between samples (14 to $89 \mathrm{~m} \mathrm{~g}$ soil $^{-1}$ ) and exhibited spatial structure at scales $<30 \mathrm{~cm}$. The

5 composition of AMF communities was also found to exhibit significant spatial autocorrelation,

6 with correlogram analyses suggesting patchiness at scales $<50 \mathrm{~cm}$. Supportive of overall AMF

7 community composition analyses, individual AMF ribotypes corresponding to specific

8 phylogenetic groups exhibited distinct spatial autocorrelation. Our results demonstrate that AMF

9 diversity and abundance can be spatially structured at scales of less than $1 \mathrm{~m}$. Such small-scale

10 heterogeneity in the soil suggests that establishing seedlings may be exposed to very different,

11 location dependent AMF communities. Our results also have direct implications for

12 representative sampling of AMF communities in the field.

\section{Introduction}

14 Spatial distribution is one of the most fundamental ecological parameters for any group of

15 organisms. Community composition or structure is driven by a range of different biotic and

16 abiotic factors that can exert influences at broadly different spatial and temporal scales (Levin,

17 1992). Disentangling these interactions is a major challenge to community ecology, requiring

18 linkage of scales at which communities are measured with scales at which factors hypothesized

19 to control their composition actually operate (Huston, 1999).

20 Amongst biotic interactions influencing plant community composition and ecosystem

21 processes, the importance of mycorrhizae is becoming increasingly apparent and recent evidence

22 suggests that interrelationships exist between plant and mycorrhizal fungal communities (Harnett

23 \& Wilson, 2002; Hart et al., 2003; Leake et al., 2004). Mycorrhizal fungi can influence plant 
1 communities via a variety of mechanisms, including differential provision of benefits to different

2 plant community members, and linking plants within a fungal network that allows for interplant

3 trafficking of nutrient resources (Simard \& Durall, 2004).

$4 \quad$ While arbuscular mycorrhizal fungal (AMF) communities have been shown to differ

5 between sites, hosting plant species, habitats and ecosystem types (e.g. Helgason et al., 1999,

6 2002; Daniell et al., 2001; Husband et al., 2002), surprisingly little attention has been given to

7 their community distribution at small spatial scales. Recent evidence indicating significant

8 differences between AMF communities of co-occurring plants (Vandenkoornhuyse et al., 2002,

9 2003) would suggest host preferences as a potential mechanism promoting small-scale spatial

10 structure. There is also a growing literature describing differences in life-history strategies

11 among AMF taxa (e.g. Hart \& Reader, 2002; Maherali \& Klironomos, 2007). Interspecific

12 differences in reproduction, dispersal, growth and environmental tolerances would be expected

13 to result in formation of a spatial structure. Clearly, interspecific interactions are factors

14 contributing strongly to the assembly of ectomycorrhizal fungal communities (Koide et al., 2004;

15 Kennedy et al., 2007) and model AMF communities (Maherali \& Klironomos, 2007). Specific

16 species responses to physico-chemical gradients (e.g. nutrients, $\mathrm{pH}$, soil texture and structure)

17 have also been documented (e.g. Lekberg et al., 2007) and could influence both large and small-

18 scale spatial stratification of AMF community composition.

19 Knowledge of how AMF are distributed in the environment is critical for determining

20 spatial scales relevant for understanding relationships between AMF communities, plant

21 communities and ecosystem processes. Such knowledge is also central to elucidation of

22 belowground interactions that drive variance in plant community assemblages and to determine 
1 what scales are most appropriate for capturing the effects of AMF community compositional

2 changes.

Many different factors can potentially influence seedling establishment in terrestrial

4 ecosystems, including the presence or composition of AMF communities (van der Heijden,

5 2004). If AMF communities are spatially homogeneous over short distances, relatively similar

6 host/mutualist relationships would be expected. On the other hand, if small-scale spatial

7 heterogeneity is pronounced, then at least the potential for differential benefit due to specific

8 AMF community differences exists.

9 In this study we wished to examine the distribution of AMF in a grassland ecosystem at

10 relatively small spatial scales relevant to individual plants from the perspective of seedling

11 recruitment. Specifically, we asked the following questions: (a) On what scales is spatial

12 structure in AMF abundance and community composition apparent? (b) Is soil AMF community

13 spatial structure significantly explained by knowledge of plant species identity and aboveground

14 location? (c) Is AMF community composition a function of AMF abundance?

\section{Methods}

\section{Study site, sample strategy and plant measures}

17 Two sites, located $5 \mathrm{~km} \mathrm{~N}$ of Missoula, MT (USA) and separated by a distance of approximately

$1825 \mathrm{~m}$, were randomly selected on a gentle slope dominated by native grass species Festuca

19 idahoensis Elmer, Koeleria cristata (Ledeb.) Schult, Pseudoroegneria spicata (Pursh) A. Löve

20 ssp. spicata and Hesperostipa comata (Trin. \& Rupr.) Barkworth ssp. comata (for a more

21 detailed site description see: Lutgen et al., 2003; Mummey et al., 2006). Although minor forb

22 cover is present on areas surrounding our study plots, no non-mycorrhizal plant species were

23 identified within our plots that would serve to disrupt AMF community or abundance measures. 
On each site a $1 \mathrm{~m}^{2}$ frame was placed with sides corresponding to eastern and northern

2 directions. Thirty-three soil samples $(5 \mathrm{~cm}$ diameter, $10 \mathrm{~cm}$ depth) were collected from each plot

3 at coordinates designed to facilitate spatial analyses (Halvorson et al., 1994; Fig. 1a). The spatial

4 coordinates and species identity of all plants within each plot was carefully documented. For

5 each plant individual, aboveground growth was harvested to ground level, dried $\left(60^{\circ} \mathrm{C}\right.$ for $\left.24 \mathrm{~h}\right)$

6 and weighed to determine its aboveground biomass.

$7 \quad$ Extraradical hyphal length analyses

8 Extraradical AMF hyphal lengths were measured in each soil core according to Rillig et al.

9 (1999). This technique involves aqueous extraction of hyphae from soil samples (4 g) and

10 subsequent determination of AMF hyphae at 200x magnification. Hyphal lengths were estimated

11 using the line intersect method as described in Tennant (1975) and Jakobsen et al. (1992).

\section{AMF community analyses: T-RFLP analysis optimization and validation}

13 Prior to conducting T-RFLP analysis of samples, T-RFLP analysis methods were optimized and

14 validated as described in Mummey and Rillig (2007). Briefly, DNA was extracted from plant

15 roots and soils near our study plots and a portion of the AMF ribosomal large subunit gene

16 amplified via polymerase chain reaction (PCR) using unlabeled primers in reactions as described

17 below. These products were cloned and sequenced, as described previously (Mummey \& Rillig,

18 2007). The computer program TRFSEQ (available from corresponding author upon request) was

19 used to conduct simulated digestion of cloned sequences (GenBank accession numbers

20 DQ468685 to DQ468824) with a broad range of restriction enzymes. This allowed for selection

21 of restriction enzymes optimal for T-RFLP-based discrimination of the AMF diversity in our

22 study plots. We used the following criteria to select restriction enzymes: (1) Overall ability to

23 discriminate AMF diversity; (2) yielding unique terminal restriction fragment sizes (T-RF) for 
1 each phylogenetic group that were as pronounced as possible; (3) T-RF sizes were greater than

$240 \mathrm{bp}$ to allow for optimal size calling. These analyses indicated that the reaction conditions were

3 highly specific to Glomeromycota of our study sites. Of the restriction enzymes examined, two

4 (Taq I and Alu I) were found to best meet the above criteria and were used in all subsequent

5 analyses.

\section{AMF community analyses: procedures}

7 For analysis of samples from our study sites, each soil core was homogenized by manual

8 kneading and shaking in plastic bags. Whole community DNA was extracted from subsamples

9 (0.4 g wet weight) using the PowerSoil DNA isolation kit (MoBio Laboratories, Carlsbad, CA).

10 Bead-beating utilized a Geno/Grinder ${ }^{\mathrm{TM}} 2000$ (SPEX CentriPrep, Inc.). To consistently obtain

11 sufficient amounts of PCR product for analysis, PCR amplification of soil DNA extracts

12 consisted of two PCR rounds, the first employing the "general fungal" primer pair LR1 and

13 FLR2 (Trouvelot et al., 1999; van Tuinen et al., 1998) and the second using AMF-specific

14 primers FLR3 and FLR4 (Gollotte et al., 2004). The $25 \mu$ reaction mixtures included $1 \mu$ soil

15 extracted template DNA or product from the previous PCR, 100 pmol of each deoxynucleoside

16 triphosphate, 10 pmol of each primer, 2 U HotMaster ${ }^{\mathrm{TM}}$ Taq DNA polymerase (Eppendorf,

17 Hamburg, Germany) and 0.6 M betaine. Thermal cycling for all reactions included an initial

18 denaturing step of $95^{\circ} \mathrm{C}$ for 5 minutes, 25 cycles (primer pair LR1 and FLR2) or 30 cycles

19 (primer pair FLR3 and FLR4) consisting of $1 \mathrm{~min}$ at $95^{\circ} \mathrm{C}, 1 \mathrm{~min}$ at $58^{\circ} \mathrm{C}$ and $1 \mathrm{~min}$ at $65^{\circ} \mathrm{C}$,

20 followed by a final extension step of $65^{\circ} \mathrm{C}$ for $10 \mathrm{~min}$.

21 Products of two separate reactions were combined and purified using the GenCatch ${ }^{\mathrm{TM}}$

22 PCR cleanup kit (Epoch Biolabs, Inc. Sugar Land, TX) and subsequently quantified by image

23 analysis of agarose gels following electrophoresis with Low DNA Mass Ladder (Invitrogen, 
1 Carlsbad, CA) as the size standard. The purified PCR products were then digested in separate

2 reactions with restriction enzymes TaqI (Fermentas, Hanover, MD) and AluI (New England

3 Biolabs, Beverly, MA). Each digestion, containing $12 \mu \mathrm{l}$ PCR product and $3 \mathrm{U}$ Alu I or Taq I in

4 the manufacturer's recommended buffer, was incubated for $4 \mathrm{~h}$ at either $37^{\circ} \mathrm{C}(\mathrm{Alu} \mathrm{I})$ or $65^{\circ} \mathrm{C}$

5 (Taq I), followed by enzyme heat inactivation at $94{ }^{\circ} \mathrm{C}$ for 10 minutes. All reactions were then

6 treated with 3 U Mung Bean endonuclease (New England Biolabs) to remove single-stranded

7 “pseudo-T-RFs” (Egert \& Friedrich, 2003).

8 For each sample T-RF size distributions were determined using an ABI 3100 automated

9 capillary DNA sequencer (Applied Biosystems, Foster City, CA) with ROX-500 (Applied

10 Biosystems) as the size standard. Fragment size determination and quantification was performed

11 using Genemapper software (Applied Biosystems). We used the Microsoft-Excel macro Treeflap

12 (Rees et al., 2004; http://www.wsc.monash.edu.au/ cwalsh/treeflap.xls) to convert each

13 fragment size present in T-RFLP profiles to the nearest integer value and to subsequently align

14 peaks against rounded sizes of the fragments. Total relative fluorescence of T-RFLP profiles

15 derived from each sample was standardized to 4000 relative fluorescence units with a minimum

16 peak height threshold of 40 fluorescence units.

\section{Data analyses}

18 Correlations between extraradical hyphal lengths and T-RF size numbers were examined using

19 SPSS software (ver. 15.0). Relationships between AMF community similarity measures and

20 extraradical hyphal lengths were examined using the Mantel test (zt software; Bonnet \& Van de

21 Peer, 2002).

22 Spatial structure of hyphal lengths and T-RF size numbers were evaluated using Moran's

23 I (Moran 1950) correlogram analyses (Cliff \& Ord, 1981). Spatial structure of AMF 
1 communities, including testing for the presence of autocorrelation, was specifically examined

2 using Mantel correlogram (Oden \& Sokal, 1986) analysis. Mantel correlograms were produced

3 by calculating normalized $r_{M}$ values for AMF community Bray-Curtis distances (Bray \& Curtis,

4 1957) within different geographic distance classes. The degree of autocorrelation within each

5 distance class was tested to determine whether it is greater or less than the overall mean

6 autocorrelation between sites. The software program PASSaGE (ver 1.1; Rosenberg, 2001) was

$7 \quad$ used to conduct these analyses.

$8 \quad$ Variance partitioning (Borcard et al., 1992; Borcard \& Legendre, 1994; Legendre \&

9 Legendre, 1998) of AMF community data was used to examine variation explained by plant

10 species identity and location and spatial structure. Spatial models for these analyses included

11 both euclidean distance (planar) and principle coordinates of neighbour matrices (PCNM).

12 PCNM spatial filtering [for detailed description of this method see Borcard \& Legendre (2002)

13 and Borcard et al. (2004)] involves eigenfunction decomposition of a truncated matrix of the

14 geographical distances between sample locations. Eigenvectors corresponding to positive

15 eigenvalues are then used as spatial descriptors. For each analysis, a number of different

16 truncation distances were examined by forward selection, compared in terms of the total amount

17 of variance explained, and the best models (axes found to account for a significant fraction of the

18 overall variance) retained for subsequent analyses.

19 The computer program PASSaGE (Rosenberg, 2001) was employed to determine sample

20 locations within 10, 15 and $20 \mathrm{~cm}$ from the base of each plant species. For both spatial models,

21 forward selection with Monte-Carlo permutation testing (Canoco software; ter Braak \&

22 Smilauer, 1998) was used to determine plant and distance classes potentially exerting a 
1 significant influence on AMF community composition. Insignificant variables $(\mathrm{P}>0.05)$ were

2 eliminated from further analyses.

3 Distance-based redundancy analysis (db-RDA; Legendre \& Anderson, 1999) was then

4 used to obtain ordinations of T-RFLP AMF community data constrained by spatial distance

5 models and plant influences. Monte Carlo permutation tests were performed to assess the

6 significance of canonical axes showing relationships between AMF community data of each

7 sample and environmental factors.

8 We also examined the spatial distributions of T-RF sizes indicated by previous analyses

9 (Mummey \& Rillig, 2007) to be diagnostic for specific AMF groups present on our study plots.

10 For these analyses spatial autocorrelation was examined using binary indicator correlogram

11 analysis (Isaaks \& Srivastava, 1989) in which samples yielding multiple T-RF sizes matching

12 specific AMF ribotypes were assigned a value of 1 and samples lacking these T-RF sizes were

13 assigned a value of 0 .

\section{Results}

\section{Plant aboveground measures}

16 Although most plant species present in Plot 1 were also present in Plot 2, their relative numbers

17 and contribution to total aboveground biomass differed (Fig. 1). Koeleria cristata, P. spicata

18 and F. idahoensis accounted for 31, 58 and $10 \%$ of the aboveground biomass of Plot 1 ,

19 respectively (Fig. 1a). Koeleria cristata, P. spicata, F. idahoensis and H. comata accounted for

$2010,28,56$ and 5\% of the aboveground biomass of Plot 2, respectively (Fig. 1b). Total

21 aboveground biomass also differed substantially between plots ( $303 \mathrm{~g}$ and $225 \mathrm{~g}$ for Plots 1 and

22 2, respectively). Mean distance between nearest neighbouring plants was found to be 10.9 and

$239.7 \mathrm{~cm}$ for Plots 1 and 2, respectively. 


\section{Abundance and distribution of AMF extraradical hyphae}

2 Despite plant biomass and species compositional differences, overall hyphal lengths did not

3 differ significantly between plots $(\mathrm{F}=0.84, \mathrm{P}=0.36)$, averaging 43 and $41 \mathrm{~m} \mathrm{~g}$ soil $^{-1}$ for Plot 1

4 and 2, respectively (Fig. 2a, b). However, hyphal lengths varied greatly between samples,

5 ranging from 14 to $89 \mathrm{~m} \mathrm{~g} \mathrm{soil}^{-1}$ for Plot 1 and 15 to $73 \mathrm{~m} \mathrm{~g} \mathrm{soil}^{-1}$ for Plot 2.

6 Correlogram analysis indicated that hyphal lengths exhibited significant positive spatial

7 autocorrelation (Moran's $I$ ) in the first distance class of each plot, while spatial autocorrelation

8 was insignificant for all other distance classes (Fig. 3a, b). Since patch size is indicated by the

9 distance at which the first near maximum negative autocorrelation value is found (Legendre \&

10 Legendre, 1998), these results would suggest patch size less than $30 \mathrm{~cm}$ for both plots.

\section{AMF community composition analyses}

12 Average T-RF numbers found per sample differed significantly between plots (Fig. 4a, b;

13 ANOVA; $\mathrm{P}<0.005)$. The number of T-RF sizes found for Plot 1 after combining all four $\mathrm{T}$ -

14 RFLP profiles for each sample ranged from 34 to 56 and averaged 45. For Plot 2 the number of

15 different T-RF sizes found per sample ranged from 22 to 46 and averaged 32.

16 Correlogram analysis of T-RF numbers indicated an insignificant trend towards increased

17 spatial autocorrelation at the shorter distance classes for both plots (Fig. 3c, d). Plot 1, similar to

18 what was found for hyphal lengths, exhibited maximum negative spatial autocorrelation near 30

$19 \mathrm{~cm}$, suggesting a trend towards patchiness at relatively small scales. In contrast, Plot 2 exhibited

20 maximal negative spatial autocorrelation at near $60 \mathrm{~cm}$, suggesting more of a gradient structure

21 or a trend towards patchiness at a relatively greater scale (Legendre \& Legendre, 1998).

22 Mantel correlograms indicated significant spatial autocorrelation for AMF community

23 composition at the shorter distance classes (Fig. 3e, f). However, positive spatial autocorrelation 
1 extended to greater distances than was apparent for hyphal lengths or T-RF numbers. Maximum

2 negative autocorrelation occurred at relatively greater distances $(45 \mathrm{~cm}$ and $55 \mathrm{~cm}$ for Plots 1 and

32 , respectively), suggesting patchiness at a relatively larger scale.

$4 \quad$ Variance due to plants

5 Partitioning the variation in community similarity measures yielded similar results for both

6 planar and PCNM models. For Plot 1, removal of spatial variability with either model indicated

7 that a small but significant amount of the overall variance in AMF community composition data

8 could be attributed to samples collected within $20 \mathrm{~cm}$ of $P$. spicata and $15 \mathrm{~cm}$ of $K$. cristata

9 plants $[8.6 \%(\mathrm{P}=0.013)$ and $9.1 \%(\mathrm{P}=0.04)$ of the variance in AMF community data explained

10 by planar and PCNM models, respectively]. Neither extraradical hyphal length nor T-RF size

11 numbers were found to be significantly related to plant location and identity after removal of

12 spatial structure with either model.

13 Removal of spatial structure in AMF community data of Plot 2 using either model

14 indicated that plant location and identity also accounted for a small but significant amount of the

15 variance, although, unlike Plot 1 , samples $<15 \mathrm{~cm}$ from the base of $K$. cristata and $F$. idahoensis

16 significantly influenced AMF community composition [8.2\% $(\mathrm{P}=0.03)$ and $8.2 \%(\mathrm{P}=0.02)$ of

17 the variance in AMF community data explained by planar and PCNM models, respectively].

18 Our previous cloning and sequencing efforts for this system were not exhaustive and

19 focused on root samples obtained near the study site which, due to differences in functional traits

20 between phylogenetic groups, may differ substantially in AMF species composition compared to

21 that of soils (Hart \& Reader, 2002; Maherali \& Klironomos, 2007). Despite this, we did find a

22 number of matches with T-RF sizes anticipated from analyses of site-specific sequence data that

23 are thought to be diagnostic for specific AMF lineages (Mummey \& Rillig, 2007). Spatial 
1 dependence was apparent for a number of ribotypes when data for the presence or absence of

2 diagnostic T-RF sizes in each sample is plotted graphically (Fig. 5). Indicator correlogram

3 analyses confirmed spatial dependence for all of the specific ribotypes depicted (Fig. 5).

4 Relationships between AMF community abundance and composition

5 Examination of correlations between T-RF size numbers and hyphal lengths indicated an

6 insignificant trend towards increased hyphal lengths with T-RF numbers for Plot $1(\mathrm{r}=0.31 ; \mathrm{P}=$

7 0.08). No relationship between these variables was detected for Plot $2(\mathrm{r}=-0.04 ; \mathrm{P}=0.83)$.

8 Similarly, Mantel tests comparing AMF community similarity with hyphal lengths indicated a

9 positive, significant relationship between these variables for Plot $1(\mathrm{r}=0.16 ; \mathrm{P}=0.014)$, but not

10 for Plot $2(\mathrm{r}=0.01 ; \mathrm{P}=0.427)$.

\section{Discussion}

12 A number of studies suggest that arbuscular mycorrhizal fungal communities are not

13 homogeneously distributed in the environment, but vary both spatially (e.g. Rosendahl \&

14 Stukenbrock, 2004) and temporally (e.g. Husband et al., 2002). While individual plants and plant

15 communities can contain distinct AMF communities that vary from each other in their

16 composition and species number (e.g. Helgason et al., 2002; Husband et al., 2002), how these

17 relationships manifest at small spatial scales in soil under the influence of plant communities is

18 poorly defined.

19 Our results, taken individually or as a whole, demonstrate that AMF abundance and

20 community composition can be definably spatially structured at scales of less than $1 \mathrm{~m}$. From the

21 perspective of establishing plants, these results suggest that small-scale spatial differences could

22 strongly influence which subsets of the AMF community seedlings are exposed. Since it has

23 been repeatedly demonstrated that plant response can vary significantly between different AMF 
1 communities or species (e.g. Klironomos, 2003; Moora et al., 2004), such small-scale spatial

2 heterogeneity could have important implications for plant establishment (van der Heijden, 2004).

While our results indicate spatial structure in small-scale AMF abundance and

4 community composition, factors influencing this spatial heterogeneity are less clear. The results

5 of variance partitioning analyses indicated that very little of the variation in our AMF abundance

6 or community composition data could be accounted for by plant species identity and

7 aboveground location. While these results appear to contrast with studies indicating significant

8 differences between AMF communities associated with neighbouring plant species (e.g.

9 Vandenkoornhuyse et al., 2002; 2003), molecular analyses of soil and root AMF communities

10 can yield very different results (Hempel et al., 2007). This may be due to differences in life

11 history strategies amongst AMF and host-specific growth responses (e.g. Bever, 2002; Maherali

$12 \&$ Klironomos, 2007). Differences resulting in alteration of sporulation times (Pringle \& Bever,

13 2002), for example, may be more apparent in analyses of soil, rather than root-inhabiting, AMF

14 communities. Additionally, it has been suggested that some AMF may also access $\mathrm{C}$ in soil from

15 sources other than host plants (Hempel et al., 2007), a hypothesis that remains to be tested.

16 Our results, contrary to what was hypothesized, did not indicate a relationship between

17 AMF diversity, as indicated by T-RF size numbers, and extraradical hyphal abundance.

18 However, Mantel test comparison of AMF community composition with abundance measures

19 indicated a significant relationship for Plot 1, suggesting that AMF species composition had

20 some influence on soil exploration by hyphae, as also found in mesocosm inoculation studies

21 (van der Heijden et al., 1998). However, this relationship was not significant for Plot 2

A number of previous studies have employed molecular tools for spatial analysis of AMF

23 communities, although typically at scales quite different from the work presented here (e.g. 
1 Husband et al., 2002; Öpik et al., 2006). For example, Rosendahl \& Stukenbrock (2004)

2 examined spatial extents of Glomus within roots in undisturbed sand dunes at $5 \mathrm{~m}$ intervals and

3 obtained evidence that Glomus species can be patchily distributed at scales approaching $10 \mathrm{~m}$.

4 Wolfe et al. (2007) used a T-RFLP-based method to assess spatial variation in AMF diversity

5 within a $2 \times 2 \mathrm{~m}$ plot situated on a calcareous fen having high plant species diversity at relatively

6 small scales (2-9 species per $20 \times 20 \mathrm{~cm}$ cell). Although AMF communities appeared to be quite

7 complex, no significant spatial autocorrelation in AMF abundance or diversity was found at the

8 scales measured.

9 Our results correspond with studies that have found AMF spores to be patchily

10 distributed in both abundance and morphology at multiple scales (Boerner et al., 1996;

11 Klironomos et al., 1999; Pringle \& Bever, 2002; Carvalho et al., 2003). Two separate studies

12 (Klironomos et al., 1999; Carvalho et al., 2003) used geostatistical methods to analyze spatial

13 distributions of spores at scales approaching those examined in our study and found strong

14 spatial autocorrelation in total spore numbers and morphologies associated with different AMF

15 groups (Glomus, Acaulospora, Scutellospora) over relatively small distances. These studies,

16 although both were conducted in shrublands, differed greatly in plant community composition

17 and soil conditions (maquis, dense scrub, clay-loam, Carvalho et al., 2003; chaparral, sandy-

18 loam, Klironomos et al., 1999). The proportion of variance in total spore numbers that could be

19 accounted for by spatial characteristics was high for both systems (99.7 and 86.7\% for Carvalho

20 and Klironomos, respectively). Moreover, the percent of variance in family-specific spore

21 numbers (Glomus, Acaulospora, Scutellospora) accounted for by spatial autocorrelation was

22 high for both studies (63.8 to 99.9\%, Carvalho et al., 2003; 22 to 95.7\%, Klironomos et al.,

23 1999). Similar to what we found for AMF community composition, spatial dependence ranged 
1 from $30 \mathrm{~cm}$ to $120 \mathrm{~cm}$ for family-specific groups in the Klironomos study and from 54 to $300 \mathrm{~cm}$

2 in the Carvalho study.

3 Our results have important implications for representative sampling. The range of values

4 obtained for hyphal lengths (Fig. 2), T-RF numbers (Fig. 4) and AMF community composition

5 found at these small scales suggest that single samples would very poorly capture the variability

6 present in a given site. For example, correlogram analysis suggests that in order to capture

7 extraradical hyphal lengths representative of this ecosystem at this specific time, multiple

8 samples would need to be collected at distance scales less than $30 \mathrm{~cm}$ (Fig. 3). Capturing all

9 ribotype diversity would likely require a much larger sampling effort, similar to what was

10 conducted here. However, if the goal of analysis is to determine spatial distributions of the

11 dominant AMF ribotypes at the field scale, sampling at or below the scale of overall AMF

12 community patch sizes indicated by our analyses $(45$ to $55 \mathrm{~cm}$ ) may be warranted.

13 Since very little of the variance in the AMF community data could be accounted for by

14 plant species identity and location, our results suggest that sampling soil AMF communities on

15 the basis of plant species aboveground location may not be optimal for small-scale analyses.

16 While AMF and host taxa preferences may occur, and may even be pronounced, aboveground

17 plant measures can poorly reflect root spatial structure or distributions (e.g. Hutchings \& John,

18 2003) potentially obscuring these relationships. Additionally, distances hyphae grow away from

19 roots can vary with AMF species (Klironomos \& Moutoglis, 1999) and these relationships would

20 be expected to be influenced by host identity. Species-specific differences in external mycelium

21 architecture and root vs. soil colonization rates (Hart \& Reader, 2004) would also be expected to

22 influence species-specific patch size.

\section{Methodological considerations}


1 Although we used restriction enzymes shown to allow for optimal discrimination of AMF

2 species or phylotypes (Mummey \& Rillig, 2007), it is still unclear to what extent these analyses

3 are suitable for evaluation of species richness. There were T-RF sizes present in sample T-RFLP

4 profiles which did not match sizes anticipated from simulated digestion of sequences cloned

5 from plant roots near the study plots (data not shown). Additionally, in some cases T-RF sizes

6 can overlap for different phylogenetic groups (Mummey \& Rillig, 2007), which would lead to

7 underestimation of diversity. The extent to which this occurred in this study is not known. Also,

8 since no single current analysis method would be expected to capture all AMF diversity

9 (Redecker et al., 2003), including analyses employing the PCR primers used in this study

10 (Mummey \& Rillig, 2007), it cannot be ruled out that AMF species of importance were missed

11 by our analyses.

12 A drawback to analysis of soil extracted whole-community DNA is that it is not possible

13 to determine which fungal structures (such as spores or extraradical hyphae) the detected rRNA

14 genes are predominantly derived. Thus, it is possible that these analyses predominantly capture

15 LSU rRNA genes from active structures, such as hyphae, and inactive structures, such as spores,

16 in different areas. Nevertheless, calculations in Hempel et al. (2007) indicate that spores

17 probably contributed fairly little to the DNA isolated from soil compared to extraradical hyphae.

\section{Conclusions}

19 Microbial eukaryotes clearly exhibit spatial structure at a variety of scales (Green et al., 2004),

20 and AMF are no exception. Given the tight links of AMF communities with plant community

21 composition (Hart et al., 2003) and ecosystem functioning (Rillig, 2004; Rillig \& Mummey,

22 2006) it is particularly important to know about the spatial heterogeneity of AMF. Here we

23 demonstrate that AMF community spatial structure is detectable at small scales $(<1 \mathrm{~m})$ in a 
1 seemingly homogenous grassland, using sample sizes $(5 \mathrm{~cm}$ diameter) adequately representing

2 the recruitment 'neighbourhood' of seedlings; clearly, this phenomenon needs to be examined in

3 other ecosystems and over several scales.

4

\section{Acknowledgements}

6 This work was supported by grants from NSF Ecology (0515904) and USDA-CSREES (2005-

7 35320-16267).

9 References

10 Bever JD (2002) Host-specificity of AM fungal population growth rates can generate feedback $11 \quad$ on plant growth. Plant Soil 244: 281-290.

12 Bonnet E \& Van de Peer Y (2002) zt: a software tool for simple and partial Mantel tests. J Stat $13 \quad$ Software 7: 1-12.

14 Borcard D, Legendre P \& Drapeau P (1992) Partialling out the spatial component of ecological $15 \quad$ variation. Ecology 73: 1045-1055.

16 Borcard D \& Legendre P (1994) Environmental control and spatial structure in ecological 17 communities: an example using oribatid mites (Acari, Oribatei). Environ Ecol Stat 1: 37$18 \quad 61$.

19 Borcard D \& Legendre P (2002) All-scale spatial analysis of ecological data by means of 20 principal coordinates of neighbor matrices. Ecol Modeling 153: 51-68.

21 Borcard D, Legendre, P, Avois-Jacquet, C \& Tuomisto H (2004) Dissecting the spatial structure 22 of ecological data at multiple scales. Ecology 85: 1826-1832.

23 Boerner REJ, DeMars BG \& Leicht PN (1996) Spatial patterns of mycorrhizal infectiveness 
of soils along a successional chronosequence. Mycorrhiza 6: 79-90.

2 Bray RJ \& Curtis JT (1957) An ordination of the upland forest communities of south Wisconsin. Ecol Monogr 27: 325-349.

4 Carvalho LM, Correia PM, Ryel RJ \& Martins-Loução AM (2003) Spatial variability of arbuscular mycorrhizal fungal spores in two natural plant communities. Plant Soil 251: 227-236.

7 Cliff AD \& Ord JK (1981) Spatial processes - Models and applications. Pion, London.

Daniell TJ, Husband R, Fitter AH \& Young JPW (2001) Molecular diversity of arbuscular mycorrhizal fungi colonising arable crops. FEMS Microb Ecol 36: 203-209.

Egert M \& Friedrich MW (2003) Formation of pseudo-terminal restriction fragments, a PCRrelated bias affecting terminal restriction fragment length polymorphism analysis of microbial community structure. Appl Environ Microbiol 69: 2555-2562.

Gollotte A, van Tuinen D \& Atkinson D (2004) Diversity of arbuscular mycorrhizal fungi colonizing roots of the grass species Agrostis capillaris and Lolium perenne in a field experiment. Mycorrhiza 14: 111-117.

Green JL, Holmes AJ, Westoby M, Oliver I, Briscoe D, Dangerfield M, Gillings M \& Beattie A (2004) Spatial scaling of microbial eukaryote diversity. Nature 432: 747-750.

Halvorson JJ, Bolton H, Smith JL \& Rossi RE (1994) Geostatistical analysis of resource islands under Artemisia tridentate in the shrub-steppe. Great Basin Nat 54: 313-328.

Hart MM \& Reader RJ (2002) Taxonomic basis for variation in the colonization strategy of arbuscular mycorrhizal fungi. New Phytol 153: 335-344.

Hart MM, Reader RJ \& Klironomos JK (2003) Plant coexistence mediated by arbuscular mycorrhizal fungi. Trends Ecol Evol 18: 418-423. 
1 Hartnett DC \& Wilson GWT (2002) The role of mycorrhizas in plant community structure and dynamics: lessons from grasslands. Plant Soil 244: 319-333.

Helgason T, Fitter AH \& Young JPW (1999) Molecular diversity of arbuscular mycorrhizal fungi colonizing Hyacinthoides no-scripta (bluebell) in a seminatural woodland. Mol Ecol 8: 659-666.

Helgason T, Merryweather JW, Denison J, Wilson P, Young JPW \& Fitter AH (2002) Selectivity and functional diversity in arbuscular mycorrhizas of co-occurring fungi and plants from a temperate deciduous woodland. J Ecol 90: 371-384.

Hempel S, Renker C \& Buscot F (2007) Differences in the species composition of arbuscular mycorrhizal fungi in spore, root and soil communities in a grassland ecosystem. Environ Microbiol 9: 1930-1938.

Husband R, Herre EA, Turner SL, Gallery R \& Young JPW (2002) Molecular diversity of arbuscular mycorrhizal fungi and patterns of host association over time and space in a tropical forest. Mol Ecol 11: 2669-2678.

Huston MA (1999) Local processes and regional patterns: appropriate scales for understanding variation in the diversity of plants and animals. Oikos 86: 393-401.

Hutchings MJ \& John EA (2003) Distribution of roots in soil, and root foraging activity. In: de Kroon H, Visser EJW (Eds.) Root Ecology. Springer, Heidelberg, Germany.

Isaaks EH \& Srivastava RM (1989) An Introduction to Applied Geostatistics. Oxford University Press, New York.

Jakobsen I, Abbott LK \& Robson AD (1992) External hyphae of vesicular-arbuscular mycorrhizal fungi associated with Trifolium subterraneum L. spread of hyphae and phosphorus inflow into roots. New Phytol 120: 371-380. 
1 Kennedy PG, Hortal S, Bergemann SE \& Bruns TD (2007) Competitive interactions among

11 Koide RT, Xu B, Sharda J, Lekberg Y \& Ostiguy N (2004) Evidence of species interactions three ectomycorrhizal fungi and their relation to host plant performance. J Ecol 95: 13381345.

Klironomos JN, Rillig MC \& Allen MF (1999) Designing field experiments with the help of semi-variance and power analyses. Appl Soil Ecol 12: 227-238.

Klironomos JN \& Moutoglis P (1999) Colonization of nonmycorrhizal plants by mycorrhizal neighbors as influenced by the collembolan, Folsomia candida. Biol Fert Soils 29: 277281.

Klironomos JN (2003) Variation in plant response to native and exotic arbuscular mycorrhizal fungi. Ecology 84: 2292-2301. within an ectomycorrhizal community. New Phytol 165: 305-316.

Leake J, Johnson D, Donnelly D, Muckle G, Boddy L \& Read D (2004) Networks of power and influence: the role of mycorrhizal mycelium in controlling plant communities and agroecosystem functioning. Can J Bot 82: 1016-1045.

Legendre P \& Anderson MJ (1999) Distance-based redundancy analysis: testing multispecies responses in multifactorial ecological experiments. Ecol Monogr 69: 1-24.

Legendre P \& Gallagher ED (2001) Ecologically meaningful transformations for ordination of species data. Oecologia 129: 271-280.

Legendre P \& Legendre L (1998) Numerical Ecology. $2^{\text {nd }}$ edition. Elsevier. Amsterdam.

Lekberg Y, Koide RT, Rohr JR, Aldrich-Wolfe L \& Morton JB (2007) Role of niche restrictions and dispersal in the composition of arbuscular mycorrhizal fungal communities. $J$ Ecol 95: $95-105$. 
1 Levin SA (1992) The problem of pattern and scale in ecology. Ecology 73: 1943-1967.

2 Lutgen ER, Clairmont DL, Graham J \& Rillig MC (2003) Seasonality of arbuscular mycorrhizal 3 hyphae and glomalin in a western Montana grassland. Plant Soil 257: 71-83.

4 Maherali H \& Klironomos JN (2007) Influence of phylogeny on fungal community assembly $5 \quad$ and ecosystem functioning. Science 22: 1746-1748.

6 Moora M, Öpik M, Sen R \& Zobel M (2004) Native arbuscular mycorrhizal fungal communities 7 differentially influence the seedling performance of rare and common Pulsatilla species. $8 \quad$ Funct Ecol 18: 554-562.

9 Moran PAP (1950) Notes on continuous stochastic phenomena. Biometrika 37: 17-23.

10 Mummey DL \& Rillig MC (2006) The invasive plant species Centaurea maculosa alters 11 arbuscular mycorrhizal fungal communities in the field. Plant Soil 288: 81-90.

12 Mummey DL \& Rillig MC (2007) Evaluation of LSU rRNA-gene PCR primers for the study of 13 arbuscular mycorrhizal fungal communities via terminal restriction fragment length 14 polymorphism analysis. J Microb Meth 70: 200-204.

15 Oden NL \& Sokal RR (1986) Directional autocorrelation: an extension of spatial correlograms to 16 two dimensions. Syst Zool 35: 608-617.

17 Öpik M, Moora M, Liira J \& Zobel M (2006) Composition of root-colonizing arbuscular mycorrhizal fungal communities in different ecosystems around the globe. $J$ Ecol 94: 778-790.

Pringle A \& Bever JD (2002) Divergent phenologies may facilitate the coexistence of arbuscular mycorrhizal fungi in a North Carolina grassland. Am J Botany 89: 1439-1446.

22 Redecker D, Hijri I, Wiemken A (2003) Molecular identification of arbuscular mycorrhizal fungi 23 in roots: Perspectives and problems. Folia Geobot 38: 113-124. 
1 Rees GN, Baldwin DS, Watson GO, Perryman S \& Nielsen DL (2004) Ordination and significance testing of microbial community composition derived from terminal restriction fragment length polymorphisms: application of multivariate statistics. Antonie van Leeuwenhoek 86: 339-347.

Rillig MC, Field CB \& Allen MF (1999) Soil biota responses to log-term atmospheric $\mathrm{CO}_{2}$ enrichment in two California annual grasslands. Oecologia 119: 572-577.

Rillig MC (2004) Arbuscular mycorrhizae and terrestrial ecosystem processes. Ecol Lett 7: 740-754.

Rillig MC \& Mummey DL (2006) Mycorrhizas and soil structure. New Phytol 171: 41-53.

Rosenberg MS (2001) PASSAGE. Pattern Analysis, Spatial Statistics, and Geographic Exegesis. Version 1.1. Department of Biology, Arizona State University, Tempe, AZ.

Rosendahl S \& Stukenbrock EH (2004) Community structure of arbuscular mycorrhizal fungi in undisturbed vegetation revealed by analyses of LSU rDNA sequences. Mol Ecol 13: 3179-3186.

Simard SW \& Durall DM (2004) Mycorrhizal networks: a review of their extent, function, and importance. Can J Bot 62: 1140-1165.

Tennant D (1975) A test of a modified line intersect method of estimating root length. $J$ Ecol 63:

995-1001.

ter Braak CJF \& Smilauer P (1998) CANOCO reference manual and user's guide to CANOCO for Windows: software for canonical community ordination (Version 4). Center for Biometry, Wageningen, the Netherlands.

Trouvelot S, van Tuinen D, Hijri M \& Gianinazzi-Pearson V (1999) Visualisation of ribosomal 
DNA loci in spore interphasic nuclei of glomalean fungi by fluorescence in situ hybridization. Mycorrhiza 8: 203-206.

Vandenkoornhuyse P, Husband R, Daniell TJ, Watson IJ, Duck JM, Fitter AH \& Young JPW (2002) Arbuscular mycorrhizal community composition associated with two plant species in a grassland ecosystem. Mol Ecol 11: 1555-1564.

Vandenkoornhuyse P, Ridgway KP, Watson IJ, Fitter AH \& Young JPW (2003) Co-existing grass species have distinctive arbuscular mycorrhizal communities. Mol Ecol 12: 30853095.

van der Heijden MGA, Klironomos JN, Ursic M, Moutoglis P, Streitwolf-Engel R, Boller T, Wiemken A, Sanders IR (1998) Mycorrhizal fungal biodiversity determines plant biodiversity, ecosystem variability and productivity. Nature 396: 69-72

van der Heijden MGA (2004) Arbuscular mycorrhizal fungi as support systems for seedling establishment in grassland. Ecol Lett 7: 293-303.

van Tuinen D, Jacquot E, Zhao B, Gollotte A \& Gianinazzi-Pearson V (1998) Characterization of root colonization profiles by a microcosm community of arbuscular mycorrhizal fungi using 25S rDNA-targeted nested PCR. Mol Ecol 7: 879-887.

Wolfe BE, Mummey DL, Rillig MC \& Klironomos JN (2007) Small-scale spatial heterogeneity of arbuscular mycorrhizal fungal abundance and community composition in a wetland plant community. Mycorrhiza 17: 175-183. 


\section{$1 \quad$ Legends for Figures}

2 Fig. 1. Sample strategy and plant locations, species identities and aboveground biomass (dry

3 weight, g) for Plots 1 and 2. Symbols represent locations for Koeleria cristata (a),

4 Pseudoroegneria spicata $(\bullet)$, Festuca idahoensis $(\boldsymbol{\Delta})$, Stipa comata $(*)$, Poa species, (०), and

5 mixed weedy grasses (j).

6 Fig. 2. Upper panels depict histograms representing AMF extraradical hyphal lengths estimated

7 for samples of Plots 1 and 2. Lower panels depict sample location on each plot with symbol size

8 corresponding to extraradical AMF hyphal length estimated for each sample.

9 Fig. 3. Correlograms depicting spatial autocorrelation for extraradical AMF hyphal lengths,

10 numbers of T-RF sizes detected, and AMF community composition for each plot. Solid symbols

11 indicate significant spatial autocorrelation for samples within a distance class. A minimum of 60

12 sample pairs were analyzed in each distance class for each plot.

13 Fig. 4. Upper panels depict histograms representing the frequency at which specific numbers of

14 different T-RF sizes were detected in samples of Plots 1 and 2. Lower panels depict sample

15 locations on each plot with symbol size corresponding with the number of T-RF sizes detected in 16 each sample.

17 Fig. 5. (A) Plots depicting the spatial location of soil samples. Large symbols indicate the

18 presence of T-RF sizes matching a specific AMF phylogenetic group for which site-specific

19 sequence data is available. Open symbols indicate samples for which such T-RF sizes were not

20 detected. (B) Correlograms depicting spatial autocorrelation with lag distance. Information

21 pertaining to plot identity, phylogenetic affiliation of the ribotype being examined and GenBank

22 accession number for a representative sequence cloned from near the study site are depicted on

23 the right. *As defined in Mummey and Rillig (2007). 
(a) Sample locations

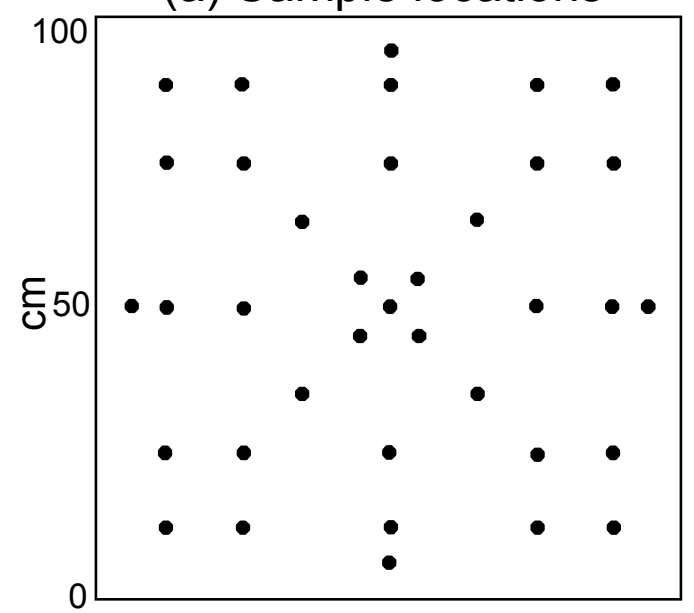

(b) Plot 1 Plants

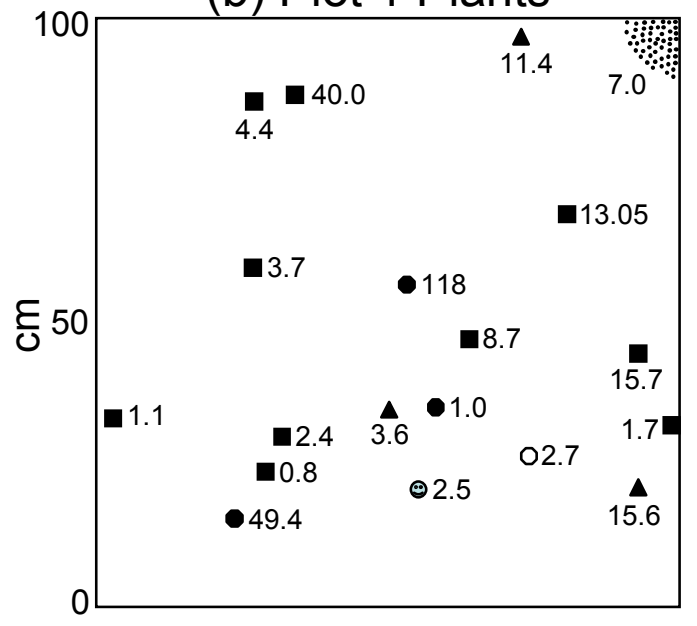

(c) Plot 2 Plants

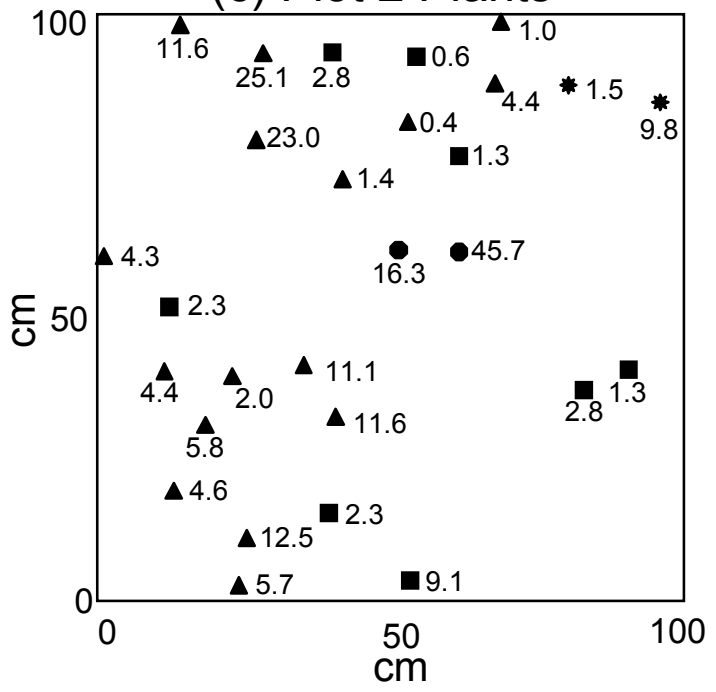



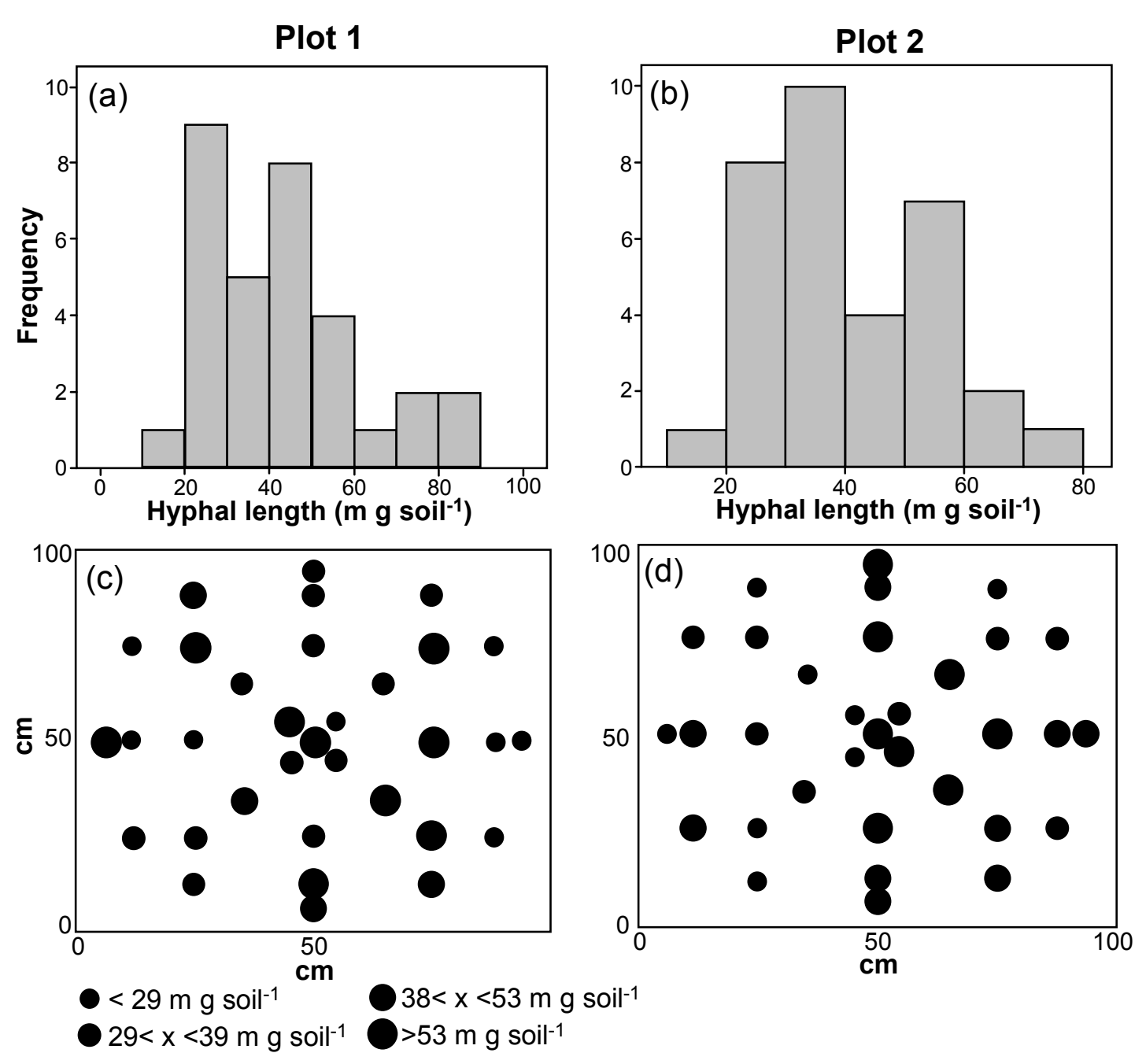

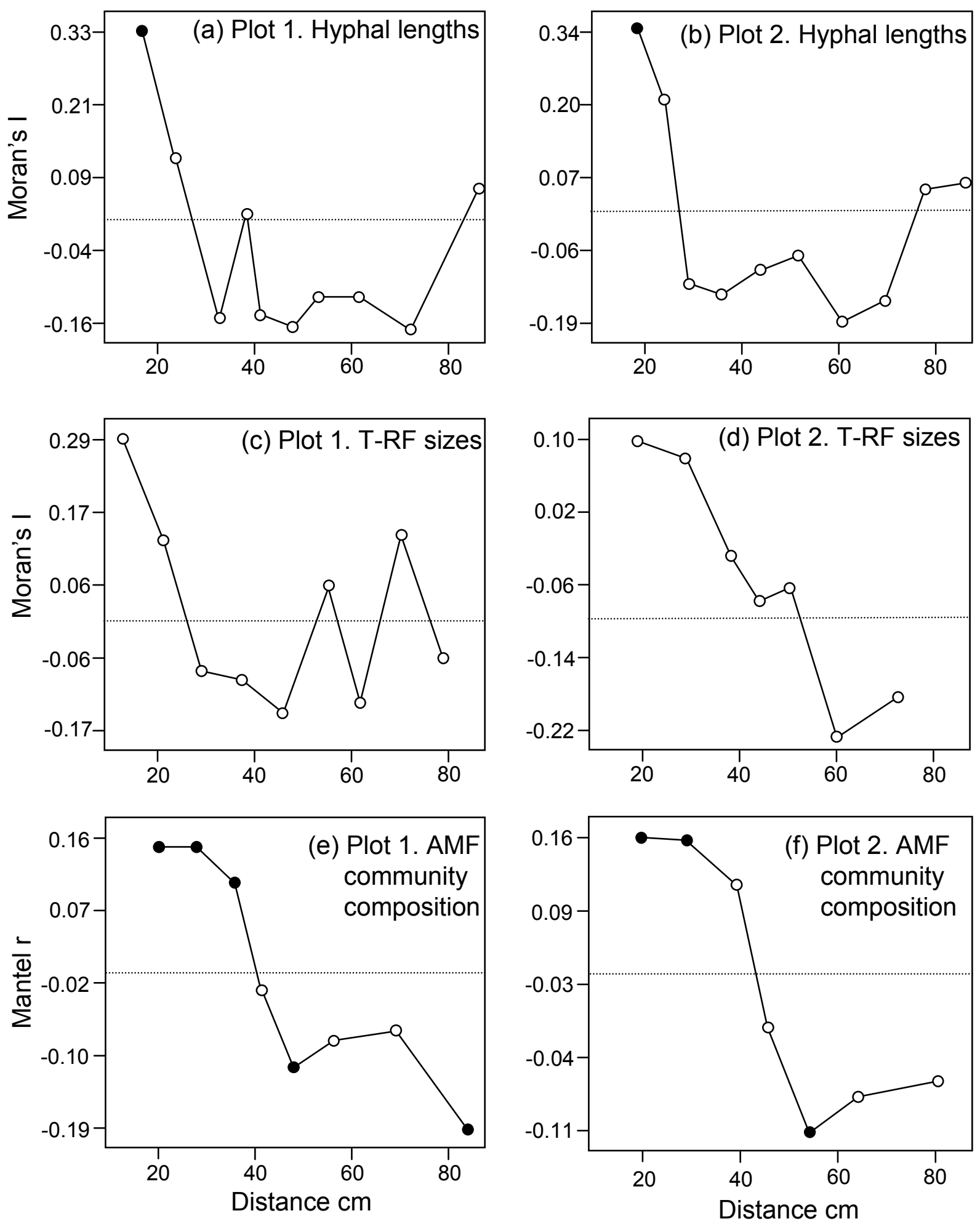
Plot 1
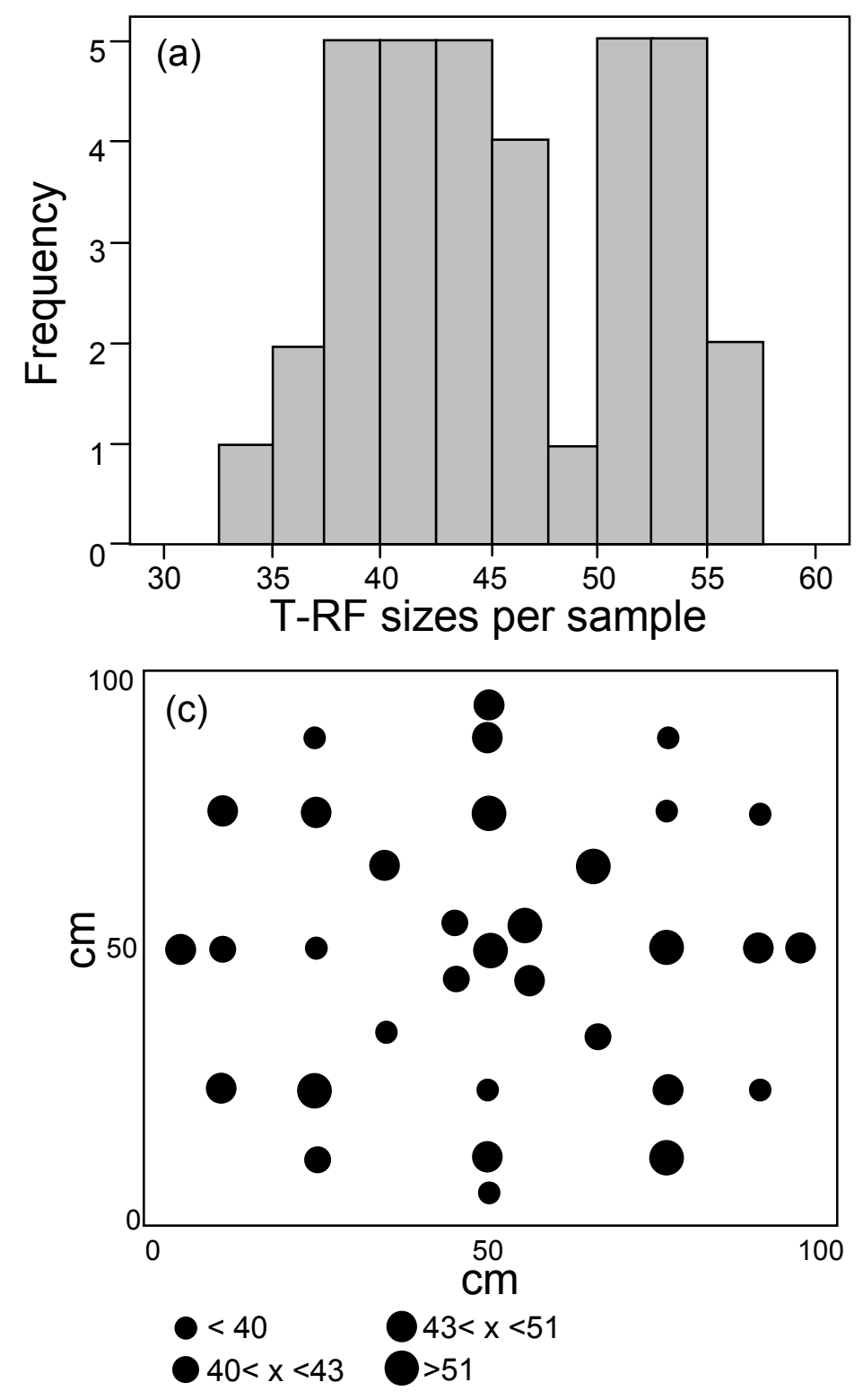

Plot 2
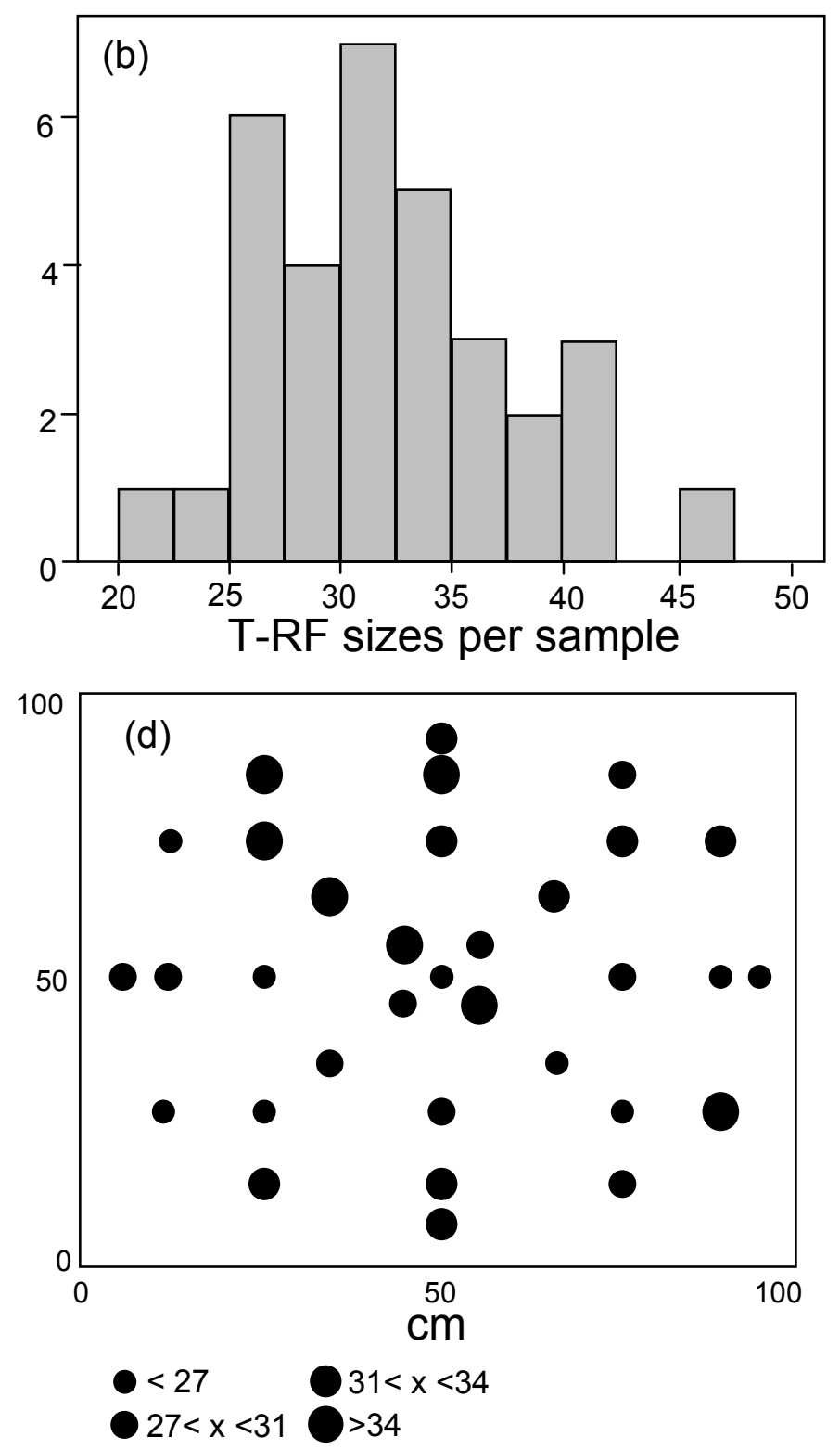

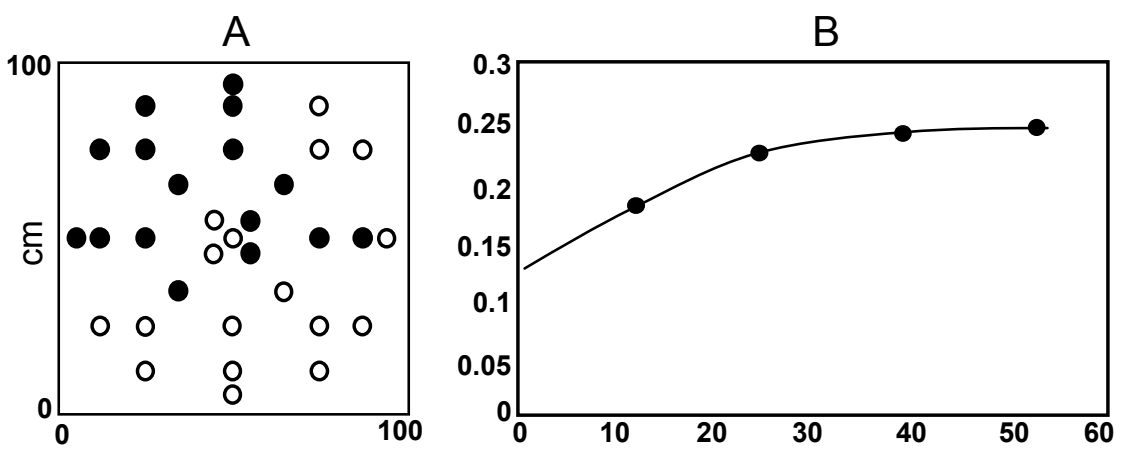

Plot 1

Glomus B, Group 28*

Ref: DQ468801
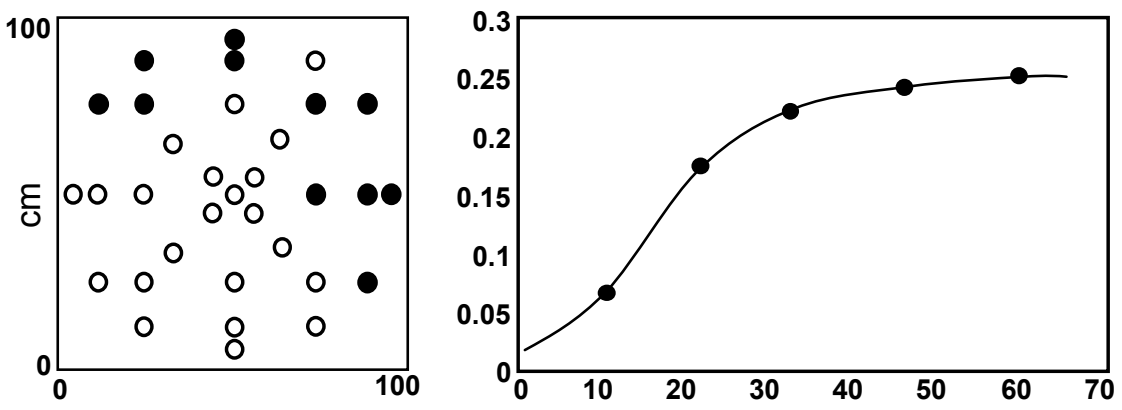

Plot 1

Glomus A, G. intradices

Ref: DQ468719
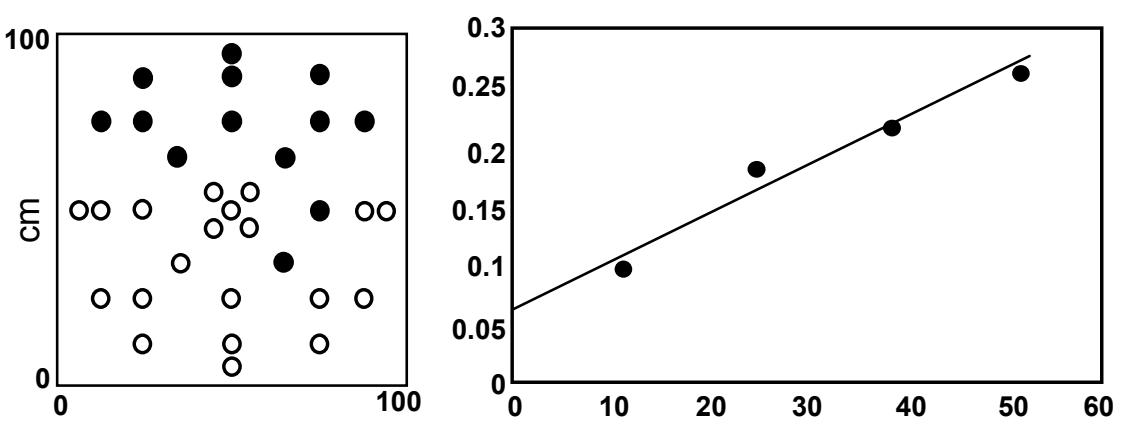

Plot 2

Glomus A, G. mosseae,

Ref: DQ677413
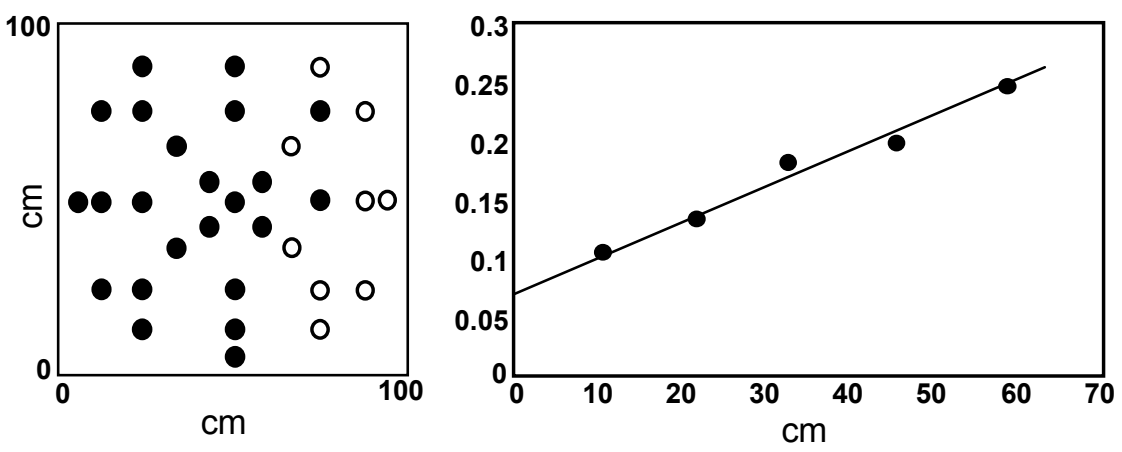

Plot 2

Glomus A, G. intradices,

Ref: DQ468719 